\title{
New Treatment Horizons for Deep Vein Thrombosis in Cancer Patients
}

\section{Caio Teixeira dos Santos ${ }^{1 *}$, Alex Pereira Ramos ${ }^{1}$, Ramon Magro Ferreira ${ }^{1}$, Bárbara Luíza Meireles Pinheiro ${ }^{1}$, Raul Ferreira de Souza Machado ${ }^{1}$, Indiara Iris de Oliveira Araujo ${ }^{1}$ and Bruno Henrique Rala de Paula ${ }^{1,2}$}

${ }^{1}$ Vassouras University, Rio de Janeiro, Brasil

${ }^{2}$ Medical Oncologist and Breast Cancer Researcher, INCA

*Corresponding author: Caio Teixeira dos Santos, Vassouras University, Rio de Janeiro,

Received Date: October 08, 2019

Brasil.

\section{Mini Review}

Venous thromboembolism (VTE), clinically manifested as deep vein thrombosis (DVT) or pulmonary embolism (PE). It is the third most common acute cardiovascular syndrome behind acute myocardial infarction and stroke [1]. It may occur before, during or after cancer diagnosis, with a relatively high incidence in cancer patients, ranging from 15 to $50 \%$ [2]. Thrombotic events are reported as the second leading cause of mortality in these patients; the main cause is death due to cancer itself [3]. VTE treatment when associated with cancer is complex, related to the high risk of bleeding and recurrent VTE [2]. The basis of acute VTE management in patients with or without cancer is generally equal. However, an individual management is necessary due to comorbidities, drug interactions and other kinds of approach. For therapeutic decision, patient choice, treatment goals and life expectancy should be taken into consideration [4]. Cancer patients without contraindications and kidney failure, low molecular weight heparin (LMWH) is recommend in the immediate anticoagulation - first five days - as monotherapy. In case of a glomerular filtration rate lower than 30 milliliters per minute, intravenous unfractionated heparin (UFH) is indicated, but it's also accepted an approach of LMWH guided by anti-Xa levels. If anticoagulation needs to be suspended or reversed in a short time, UFH should be preferred [5]. Renal and hepatic function, hemodynamic instability, comorbidities, moderate to severe edema, oral drug absorption capacity, medical cost, among others, are, as in patients without cancer, factors that interfere with the choice of therapy in patients with malignancy, [6] as shown in Table 1 (Table 1).

Table 1: Advantages and disadvantages of anticoagulant drugs in clinical practice $[4,8,9,17-20]$.

\begin{tabular}{|c|c|c|}
\hline Anticoagulant & Advantages & Disadvantages \\
\hline \multirow{3}{*}{$\begin{array}{l}\text { Unfractionated } \\
\text { heparin (UFH) }\end{array}$} & $\begin{array}{l}\text { First choice in patients with severe renal failure, hemodynamic instability, } \\
\text { extensive clot, reversal necessity, and obesity; }\end{array}$ & Higher risk of heparin-induced thrombocytopenia; \\
\hline & Lower cost when compared to LMWH; & PTTa monitoring required; \\
\hline & Possibility of acute discontinuation. & $\begin{array}{l}\text { Immediate } \\
\text { anticoagulation is performed IV (only at hospital). }\end{array}$ \\
\hline \multirow{4}{*}{$\begin{array}{l}\text { Low molecular } \\
\text { weight heparina } \\
\text { (LMWH) }\end{array}$} & $\begin{array}{l}\text { Preferred for initial anticoagulation in most patients with active malig- } \\
\text { nancy and acute VTE; }\end{array}$ & Subcutaneous administration; \\
\hline & The chosen one for early anticoagulation in pregnancy; & Higher cost than HNF; \\
\hline & Laboratory monitoring is not required; & \multirow{2}{*}{ Impossibility of reversal. } \\
\hline & May be prescribed in outpatient therapy. & \\
\hline
\end{tabular}




\begin{tabular}{|c|c|c|}
\hline \multirow{5}{*}{$\begin{array}{l}\text { Factor } \mathrm{X}_{\mathrm{a}} \text { and } \\
\text { thrombin inhibitors }\end{array}$} & $\begin{array}{c}\text { Rivaroxaban and apixaban approved for VTE } \\
\text { monotherapy; }\end{array}$ & $\begin{array}{l}\text { Contraindicated for treatment of PTE in hemody- } \\
\text { namically unstable patients; }\end{array}$ \\
\hline & Oral administration; & $\begin{array}{l}\text { Contraindicated for patients with severe kidney } \\
\text { failure; }\end{array}$ \\
\hline & \multirow{3}{*}{ No monitoring required. } & $\begin{array}{l}\text { Safety and effectiveness not proven in pregnant } \\
\text { women; }\end{array}$ \\
\hline & & $\begin{array}{l}\text { Should not be used in patients who are likely to } \\
\text { receive thrombolytic therapy; }\end{array}$ \\
\hline & & High cost. \\
\hline \multirow{3}{*}{ Warfarin } & $\begin{array}{l}\text { Possibility of effect } \\
\text { reversal; }\end{array}$ & $\begin{array}{l}\text { Cannot be prescribed as the only initial anticoagu- } \\
\text { lant to treat PTE patients; }\end{array}$ \\
\hline & Oral administration; & INR monitoring required; \\
\hline & Low cost. & Avoid the ingestion of foods rich in vitamin $\mathrm{K}$. \\
\hline
\end{tabular}

For carefully selected patients with low-risk pulmonary thromboembolism (PTE), clinical stability, not associated with significant comorbidities or aggravating conditions, early hospital discharge and follow-up on home care may be considered. It is noteworthy that the presence of PTE can be excluded in $30 \%$ of outpatients after low D-dimer results and. When present, the risk is assessed by the simplified Pulmonary Embolism Severity Index (sPESI), allowing the assessment of overall mortality in 30 days, although it demonstrates a short list of aggravating conditions $[1,7]$. Moreover, the selection criteria for patients eligible for early discharge and hospital treatment still require further validation studies. There are still gaps and disagreements and neither sPesi nor PESI (non-simplified version) were developed with the primary purpose of distinguishing patients who are candidates for an outpatient treatment [1]. Regarding the maintenance of anticoagulant therapy beyond the three to six months recommended as a therapeutic standard for patients with the first episode of VTE, some important factors should be evaluated before determining the continuation of anticoagulant medication [8]. Summarily, in two important groups continuous therapy is effective. First, patients with active cancer. The International Society of Thrombosis and Hemostasis (ISTH) establishes as active cancer those who has been diagnosed in the last six months; disease with advanced features such as metastasis and local infiltration; cancer whose treatment has occurred in the last six months; and hematologic malignancies without complete remission. Secondly, patients with a high probability of recurrence of the thromboembolic event. This methodical analysis should be performed by the assistant physician, favoring a proper screening for factors that indicate a higher risk for VTE recurrence is taken into account such as: clot permanence even after therapy, additional risk factors, and hypotension as the first sign of VTE manifestation [9]. In addition, anticoagulant therapy is also supported by a subjective perspective in which the risk-benefit of anticoagulation permanence should be considered. In patients with active cancer, there is an increased risk of $10-20 \%$ per year of recurrence of VTE compared with the general population. On the other hand, these patients are also at increased risk of bleeding under anticoagulation compared to other patients on the same therapy [10].
Despite the initial use of HPBM is generally recommended, it should be considered the previously used anticoagulant therapy whose success was achieved. Thus, the use of oral anticoagulants and warfarin is also allowed. Vitamin $\mathrm{K}$ antagonists show similar results to HPBM as a prophylaxis for TVE, including a lower mortality risk. However other side effects such as bleeding and drug interactions with chemotherapy might impair the routine use [11]. Two directacting oral anticoagulants (DOAC), rivaroxaban and endoxaban, have been evaluated and recommended by some guidelines. It must be highlighted that rivaroxaban therapeutic posology should be maintained at $20 \mathrm{mg}$, not reducing to $10 \mathrm{mg}$, as thromboembolic risk has been shown to increase in patients without cancer under this therapeutic. Although, same guidelines discourage DOAC's in not removed intraluminal malignant neoplasms due to high risk of bleeding association [9]. International guidelines such as the American Society of Clinical Oncology (ASCO), the European Society for Medical Oncology (ESMO) and the International Society of Thrombosis and Hemostasis (ISTH) still consider low molecular weight heparin, such as enoxaparin, as first-line pharmacological options for the treatment of DVT in cancer patients [12]. On the other hand, a recently published clinical trial, demonstrates a non-inferiority of rivaroxaban compared to standard enoxaparin therapy in the treatment of DVT (Einstein DVT) and another study showed a similar or better efficacy of rivaroxaban in cancer patients with thrombosis (Select-D). These results reflected in international guidelines such as ISTH 2018, in which DOAC is recommended for acute VTE treatment in cancer patients in cases of low risk of bleeding and absence of drug interactions $[13,14]$. It is important to mention that rivaroxaban was dominant in the sensitivity analysis, even with the worsening of the bleeding outcome and the low costs of enoxaparin therapy. These data corroborate those found by Leira et al. [15] and are aligned with other Brazilian studies. This result also reinforces the one published by Piedade et al. [16], whose treatment with rivaroxaban also showed a potential cost reduction when compared to enoxaparin and warfarin. Therefore, DOACs present similar efficacy to classic treatment in patients with cancer (warfarin and heparin) for uncomplicated DVT and low risk PTE. From this perspective, replacement whenever clinically possible is an important economic strategy with potential benefit for patients 
and hospital services. Due to limited advances for the subgroups of unstable or high-risk PTE patients, new studies are expected to show the best management of this population as well as costeffective analysis [17-20].

\section{Acknowledgment}

None.

\section{Conflict of Interest}

No conflict of interest.

\section{References}

1. European Society of Cardiology (2019) ESC Guidelines for the diagnosis and management of acute pulmonary embolism developed in collaboration with the European Respiratory Society (ERS). European Heart Journal pp.1-61.

2. European Society of Cardiology [internet homepage] (2019) DOACs and Venous Thromboembolism of Cancer patients: Two important trials in 2018.

3. Khorana AA, Francis CW, Culakova E, Kuderer NM, Lyman GH (2007) Thromboembolism is a leading cause of death in cancer patients receiving outpatient chemotherapy. J Thromb Haemost 5(3): 632-634.

4. Lip GY, Chin BS, Blann AD (2002) Cancer and the prothrombotic state. Lancet Oncol 3(1): 27-34.

5. Hakoum MB, Kahale LA, Tsolakian IG, Matar CF, Yosuico VE, et al. (2018) Anticoagulation for the initial treatment of venous thromboembolism in people with cancer. Cochrane Database Syst Rev 1(24).

6. Monreal M, Falgá C, Valdés M, Suárez C, Gabriel F, et al. (2006) Fatal pulmonary embolism and fatal bleeding in cancer patients with venous thromboembolism: findings from the RIETE registry. J Thromb Haemost 4(9): 1950-1956.

7. Wells PS, Kovacs MJ, Bormanis J, Forgie MA, Goudie D, et al. (1998) Expanding eligibility for outpatient treatment of deep venous thrombosis and pulmonary embolism with low-molecular-weight heparin: a comparison of patient self-injection with homecare injection. Arch Intern Med 158(16): 1809-1812.

8. Streiff MB, Holmstrom B, Angelini D, Ashrani A, Bockenstedt PL, et al. (2018) NCCN Guidelines Insights: Cancer-Associated Venous Thromboembolic Disease, Version 2. 2018. J Natl Compr Canc Netw 16(11): 1289-1303.

9. Khorana AA, Noble S, Lee AYY, Soff G, Meyer G, et al. (2018) Role of direct oral anticoagulants in the treatment of cancer-associated venous thromboembolism: guidance from the SSC of the ISTH. Journal of Thrombosis and Haemostasis 16(9): 1891-1894.

10. Albertsen IE, Nielsen PB, Søgaard M, Goldhaber SZ, Overvad TF, et al. (2018) Risk of Recurrent Venous Thromboembolism: a Danish Nationwide Cohort Study. Am J Med 131(9): 1067-1074.

11. Chai-Adisaksopha C, Iorio A, Crowther MA, de Miguel J, Salgado E, et al. (2018) Vitamin K Antagonists After 6 Months of Low-Molecular-Weight Heparin in Cancer Patients with Venous Thromboembolism. Am J Med 131(4): 430-437.

12. Sampaio TBP, Renni MJP, Costa RS (2019) Análise de Custo-efetividade e Impacto Orçamentário de Anticoagulantes no Tratamento da Trombose Venosa Profunda em Pacientes Oncológicos. Revista Brasileira de Cancerologia 65(3): e-01295.

13. The EINSTEIN Investigators (2010) Oral Rivaroxaban for Symptomatic Venous Thromboembolism. N Engl J Med 363: 2499-2510.

14. Young AM, Marshall A, Thirlwall J, Chapman O, Lokare A, et al. (2018) Comparison of an Oral Factor Xa Inhibitor with Low Molecular Weight Heparin in Patients with Cancer with Venous Thromboembolism: Results of a Randomized Trial (SELECT-D). J Clin Oncol 36(20): 20172023

15. Leira RR, Costa RS (2018) Cost-effectiveness analysis of rivaroxaban versus enoxaparin in the treatment of deep venous thrombosis in patients with gynecologic cancer. J Bras Econ Saúde 10(1): 2-8.

16. Piedade AD, Paladini L, Kashiura D, Lemmer T, Tobaruella FS, et al. (2017) Economic analysis of the treatment of venous thromboembolism with rivaroxaban in comparison with enoxaparin plus warfarin under the perspective of the Brazilian Private Healthcare System. J Bras Econ Saúde 9(1): 109-121.

17. Kearon C, Akl EA, Ornelas J, Blaivas A, Jimenez D, et al. (2016) Antithrombotic Therapy for VTE Disease: CHEST Guideline and Expert Panel Report. Chest 149(2): 315-352.

18. Kearon C, Akl EA, Comerota AJ, Prandoni P, Bounameaux H, et al. (2012) Antithrombotic therapy for VTE disease: Antithrombotic Therapy and Prevention of Thrombosis, 9th ed: American College of Chest Physicians Evidence-Based Clinical Practice Guidelines. Chest 141(2 Suppl): e419Se496S.

19. Segal JB, Streiff MB, Hofmann LV, Thornton K, Bass EB (2007) Management of venous thromboembolism: a systematic review for a practice guideline. Ann Intern Med 146(3): 211-222.

20. Merli G, Spiro TE, Olsson CG, Abildgaard U, Davidson BL, et al. (2001) Subcutaneous enoxaparin once or twice daily compared with intravenous unfractionated heparin for treatment of venous thromboembolic disease. Ann Intern Med 134(3): 191-202. 